\title{
[Disability] Justice Dictated by the Surfeit of Love: Simone Weil in Nigeria
}

\author{
Oche Onazi ${ }^{1,2}$
}

Published online: 26 July 2016

(C) The Author(s) 2016. This article is published with open access at Springerlink.com

\begin{abstract}
How is Nigeria's failure to fulfil its obligations as a signatory of the United Nations Convention on the Rights of Persons with Disabilities to be appreciated or even resolved? Answers to this are sought through a seminal criticism of human rights, namely, Simone Weil's 1942 essay Human Personality. Weil questioned the ability of human rights concepts to cause the powerful to develop the emotional dispositions of empathy for those who suffer. Weil's insights provide a convincing explanation that the indifference of Nigerian authorities towards the Convention may be accounted for by the weakness of human rights discourse to foster human capacity for empathy and care for those who suffer. Weil's criticisms will serve as a point of departure for a particular way to circumvent this inadequacy of human rights discourse to achieve disability justice in Nigeria through other means. I argue that Weil, through her concept of attention, grappled with and offers a consciousness of suffering and vulnerability that is not only uncommon to existing juridical human rights approaches, but is achievable through the active participation in the very forms of suffering and vulnerability in which amelioration is sought. To provide empirical content to this argument, I turn to a short-lived initiative of the Nigerian disability movement, which if ethico-politically refined and widely applied, can supply an action-theoretical grounding for and be combined with Weil's work to elevate agitations for disability justice above human rights to the realm of human obligations.
\end{abstract}

Keywords Attention - Disability justice · Disability simulation · Human obligations · Human rights $\cdot$ Simone Weil

Oche Onazi

o.onazi@dundee.ac.uk

1 University of Dundee, Nethergate, Dundee DD1 4HN, UK

2 Independent Social Research Foundation (ISRF), London, UK 


\section{Introduction}

The disparity between Nigeria's ratification and implementation of the United Nations Convention on the Rights of Persons with Disabilities is an invitation to reassess the efficacy or even the value of the ways in which those in positions of authority internalise human rights norms. By internalisation, I mean the ways in which moral agents absorb or assimilate international human rights norms, principles, beliefs and values, not only so that they become part of their personal and institutional characteristics, but also how the norms, principles, beliefs and values enable the moral agents to foster the human capacity to empathise with or care for those whose human rights have been violated. Understandably, internalisation as defined here depends on an understanding of human rights not simply as claims, entitlements or protections against the state, but also as a set of concepts that facilitate the mutual, even though occasionally asymmetrical, recognition of one person by another (Douzinas 2000, pp. 264-280).

Simone Weil's (1909-1943) writings are a particularly helpful way of assessing whether individuals, not only those in positions of authority but also members of society, can rely on human rights to develop dispositions that enable them to empathise with those who suffer. Weil argued that human rights are not at all helpful in this respect. She equated the effect of relying on human rights as an action-guiding principle to a type of ethical blindness to various forms of human suffering and vulnerability. The problems with human rights, for Weil, is that they are associated with a form of liberal essentialism, which misreads the sacredness of human beings; misinterprets and commodifies deep cries of human suffering; antagonises individuals; and prioritises a sort of emotional distance or detachment as a precondition for the amelioration of human suffering and vulnerability. Weil is suggesting, contrarily, that the capacity to recognise and respond to human suffering and vulnerability is contingent on a perceptual and participatory perspective- $-\mathrm{a}$ particular form of attention-that cannot be effectively achieved without love and empathy.

Weil's insights will be placed in conversation and critical engagement with international legal theories that, directly or indirectly, demonstrate how internalising human rights norms is key to resolving the disparity between treaty ratification and domestic implementation. Weil's writings are particularly helpful in showing that the problem with the international human rights system is not so much the inability of state agents to internalise human rights norms, but rather the inability of those norms to effectively cause them to respond to and care for those whose rights are being violated. In sharp contrast to the literature on international human rights law and social change, Weil's criticisms are relied upon to provide an alternative explanation for the disparity between Nigeria's international commitments and domestic implementation of the Convention. Taking this into account, I argue that Weil's criticisms of human rights together with her concept of attention can provide a different philosophical basis for the pursuit of disability justice in Nigeria. In doing so, I offer an up-to-date account of Nigerian struggles for disability justice that is accessible to non-African audiences. 
In the following section, I analyse Weil's essay Human Personality (2005 [1942]) to explain in detail the nature of and reasons for her objection to human rights. After that, I analyse the most common reasons given in the literature on internalising international human rights norms for Nigeria's continuing failure to implement the Convention. After considering possible explanations for this, I revisit Weil's thesis to argue that the problem may be more fundamental than internalising human rights norms. To conclude and to provide empirical content to this argument, I examine a short-lived initiative of the Nigerian disability movement, which if ethico-politically refined and widely applied, can supply an action-theoretical grounding for Weil's work, and show how this grounding and Weil's work can be combined to elevate the agitations for disability justice in Nigeria to the realm of human obligations.

\section{Weil's Criticisms of Human Rights}

Although important to many aspects of social, cultural, economic and political life, human rights have historically been unable to rise above doubts about their emancipatory potential. Such criticisms can be distinguished between those that fall short of outright rejection of human rights (but which question certain assumptions that underpin them) and those that dismiss outright their emancipatory potential. Those that criticise the individualistic or egoistic basis (Douzinas 2000), the natural basis (Bentham 1987 [1843], p. 53) or the legal basis (Sen 2004, p. 326) of human rights, or criticise the hierarchy assumed by civil and political rights over social, economic and cultural rights (Nickel 2005), tend to fall into the former category. Cultural relativists (American Anthropological Association 1947; Engle 2001) of various persuasions, and Karl Marx's (2007 [1844]) famous criticisms that human rights promote a kind of alienated and bourgeois individual, fall into the latter category. Although Weil's criticisms of human rights in her essay Human Personality belong to the latter category, her criticisms can be distinguished for their originality in several aspects, including the questions they raise about the ideals and freedoms intrinsic to human rights. No-one, including Marx, achieved this quite like Weil. Marx shares with Weil an interest in accounting for the consequences of the possessively individualistic nature of human rights claims. However, the uniqueness of Weil's criticisms is discernible through her overall objective of showing the ethical limitations of human rights claims in identifying and articulating significant cries of injustice. Weil's writings are also unique in that she expresses herself strongly against collective arrangements, and so she is unlikely to endorse Marx's emphasis on community-a concept that resonates with some versions of the cultural relativism literature-in his criticisms of human rights.

Weil did not write extensively about human rights; neither was her work focused on disability. As will become clearer below, Weil's objection to a kind of liberal essentialism that eschews particularity could easily apply to persons with disability, not only because of the diverse meanings of the term 'disability', but also because of the degree of sensitivity invited by reference to it. To the extent that some kinds of disability may entail some form of human suffering (Thomson-DeVeaux 2011, 
p. 113), Weil's overriding emphasis on 'affliction' in her writings may be an aid to escape such difficulties raised by reference to the term 'disability', even though reference to 'affliction' raises problems of its own (Springsted 1986, pp. 29-30). In the present article, references to affliction or human suffering are neither insensitive to the diversity of disability, nor do they equate all forms of disability with affliction or human suffering. Although Weil did not write widely about human rights, nevertheless, against conventional wisdom she offered a derisive attack on them in Human Personality. In her essay, Weil argues that human rights as concretised in the Declaration of the Rights of Man and of the Citizen 1789, particularly because of their foundations in the concept of human personality, are incapable of serving as a standard of public morality that can be relied upon to grasp the sacredness of each person in such a way that make them objects of moral recognition and respect. As Weil puts it: '[T]he notion of rights, which was launched into the world in 1789, has proved unable, because of its intrinsic inadequacy, to fulfil the role assigned to it' (2005, p. 71), and '[R]elying almost exclusively on this notion, it becomes impossible to keep one's eyes on the real problem' (2005, p. 83).

Weil's criticisms of human rights are mediated through the concept of personalism, the liberal foundation of the individual, one that is naturally endowed with certain properties, inclusive of inalienable rights. Although personalism has its origins in Emmanuel Mounier's (Dietz 1988, p. 131) work, Weil's criticisms appear to be directed at Jacques Maritain's version of the concept, which he defined as the 'metaphysical centre' (Springsted 1993, p. 169), that is, the inviolable attribute of human dignity and human being. Weil is questioning the essentialism that underlies liberalism, which has a way of abstracting human beings from concrete reality and simultaneously denying the richness, diversity and pluralism that is a characteristic of human being. Personalism is not only unable to conceive personhood nonessentially, it is also ill-equipped to understand persons as comprehensively, but equally as diversely, as possible. This is also why, as I show below, Weil objects to the categorisation of human beings. Apart from being another symptom of personalism, this categorisation is also why she gives primacy to the concept of attention as a means through which human beings can be appreciated independently of preconceptions.

Therefore, Weil's fundamental objection to human rights, particularly as a standard of public morality, lies on its erroneous understanding of the sanctity of human nature, which contributes to its inability to grasp the profound dimension of human suffering. Because human rights are founded on this notion of personalism, they are unable to convey or articulate intricate cries of human suffering. Weil suggests that human suffering can be comprehended not by an appeal to human personality - a sort of essentialist feature of individuals — but rather by appealing to what is impersonal in them. Impersonality, as such, is key to grasping the 'cry of sorrowful surprise' (Weil 2005, p. 74) that often results from the infliction of harm. She says that what is impersonal in all of us, regardless of who we are or what we may have done, is the incipient anticipation that good (not evil) will be done to us. It is this 'childlike and unchanging expectation' (2005, p. 72) of the good that opens our hearts and minds to human sacredness and is conspicuously absent from or irreducible to an agitation for a human right. 
Part of the reason why human rights are unable to grasp the profound notion of human suffering is their intrinsic commercial orientation, which causes them to come across as insincere or as superficial claims. In this sense, human rights, to use Weil's analogy, are like 'the motive which prompts a little boy to watch jealously to see if his brother has a slightly larger piece of cake' (2005, p. 72). Human rights are only helpful to a farmer who is being intimidated to sell his eggs at a minimum price and ill-suited for 'real problems' (2005, p. 83). Her perception is partly because of the common association between human rights and commercial legal transactions or relationships, particularly property and contractual legal claims and counter-claims. The effect of this is three-fold. First, because they are symptomatic of claims of traders in a marketplace or parties to a particular commercial dispute, human rights amplify the level of antagonism and envy among individuals. This is made all the more possible by the contentious language or tone in which they are asserted. Weil writes that 'when this tone is adopted, it must rely upon force in the background, or else it will be laughed at' (2005, p. 81). To assert a human right claim, to say 'I have the right...' or 'you have no right to' $(2005$, p. 83) is 'analogous to a declaration of war' (Onazi 2013, p. 52), a declaration which not only marks the beginning of hostilities, but also marks the irreversible dissolution of a relationship between associates (Waldron 1988).

Second, a related and more significant consequence of the inimical nature of human rights claims is that they are inhospitable to empathic exchanges between disputing parties, including affectionate interpretations of human rights concepts. As Weil says, human rights claims deny 'the impulse of charity on both sides' (Weil 2005 , p. 83). Here, Weil's reference to charity goes against the often derisory interpretations of the concept, which frequently present it as the antithesis to equality by demonstrating its equivalence to an almost extinct tradition of justice due to the emergence of eighteenth-century notions of natural rights. Owing to the rise and dominance of ancient Roman law (rather than liberalism), natural rights, which gave primacy to property rights, emerged as substitutes to the Greek and Christian tradition of justice that was dictated by the 'surfeit of love' (2005, p. 83). Charity, Weil says, is 'to love human beings insofar as they are nothing. That is to love them as God does' (Weil 2009, Appendix p. 19). In saying this, Weil would accept that charitable acts can be motivated for the very wrong reasons. As will be discussed in more detail in the present article in the section 'Revisiting Nigeria', Weil would no doubt agree that when the act of helping is wrongly motivated, it is 'like a sort of purchase. It buys the sufferer' (2009, p. 90).

A third consequence of the commercial nature of human rights claims, and the ethical blindness resulting from the concept of personalism, is their inability to intricately assist, grasp or convey the most silent cries of injustice. This is illustrated in Weil's analogy of labourers who are maligned for their work. She asks what specific action the labourers would take if this were to occur. Weil answers as follows: the labourers are unlikely to appeal to their 'personal rights' (Weil 2005, p. 80). Instead, they would forcefully resist the degradation of their labour, a kind of resistance that is not motivated by an 'economic demand' $(2005$, p. 80), but rather by 
an impulse from the depth of their being, fierce and desperate like a young girl who is being forced into a brothel; and at the same time it would be a cry of hope from the depth of their heart. $(2005$, p. 80)

Weil is highlighting a unique perception of justice symptomatic of human rightsbased claims, which either diminish and equate the nature of the deprivation of the labourer or the defilement of the girl with monetary claims. In doing so, Weil wants us to understand that 'the notion of rights is linked with the notion of sharing out, of exchange, of measured quantity. It has commercial flavour, essentially evocative of legal claims and arguments' (2005, p. 81). In effect, human rights commodify their grievances in the sense that the girl or the labourers must vigorously bargain for recognition of their human rights, just as the devil bargains [...] 'for the soul of some poor wretch, and someone, moved by pity, should step in and say to the devil: "It is a shame for you to bid so low; the commodity is worth at least twice as much", (2005, p. 80).

Although the profound nature of injustice particularly suffered by the girl is difficult to discern or effectively convey, even by the girl herself, it is even more difficult to articulate by 'professionals of speech' (2005, p. 80). Weil is not only touching on the difficulty of interpreting and conveying deep cries of injustices through linguistic mediums (except those-as will be demonstrated in the section 'Revisiting Nigeria' - that allow the cultivation of a kind of attentive love), but she is also suggesting that the juridification of human rights obscures the discernment and articulation of injustices (2005, p. 81). This interpretation is evident from her depiction of human rights as synonymous with 'legal claims and arguments' (2005, p. 81) and from one of Weil's most frequently cited passages:

Whenever a man cries inwardly: 'Why am I being hurt?' harm is being done to him. He is often mistaken when he tries to define the harm, and why and by whom it is being inflicted on him. But the cry itself is infallible. The other cry, which we hear so often: 'Why has some-body else got more than I have?' refers to rights. We must learn to distinguish between the two cries and to do all that is possible, as gently as possible, to hush the second one, with the help of a code of justice, regular tribunals, and the police. Minds capable of solving problems of this kind can be formed in a law school. But the cry 'Why am I being hurt?' raises quite different problems, for which the spirit of truth, justice, and love is indispensable. (2005, p. 93)

Although this passage is open to several interpretations, it most obviously shows that the concept of justice is open to two main and independent connotations depending on whether it emerges from a 'childlike and unchanging expectation' (2005, p. 72) or a cry for the good, or as the basis of a human rights claim. An agitation for a human right, most likely for all the reasons discussed above, is less demanding and can easily be appeased by professionals of speech, that is, minds formed in laws schools (2005, p. 93) together with 'a code of justice, regular tribunals, and the police' (2005, p. 93). It is not that Weil has no regard for 'professionals of speech' $(2005$, p. 80$)$, but rather she may be suggesting that the juridification of human rights often works against the poor and vulnerable, which 
she witnessed first-hand in many courts in Marseilles (Springsted 1993, p. 171). Although the poor were accorded with the best procedural standards of justice, this neither resulted in the comprehension of their suffering nor provided remedies to their grievances (1993, p. 171).

By distinguishing between two species of justice, Weil is saying that human rights are more appropriate to certain types of commercially oriented societal activity. In this sense, Weil is not outrightly rejecting human rights, but rather she is defining them within their proper limits. She is suggesting that there are things that human rights can and cannot do. Weil is in particular saying that for more serious issues, especially those that raise profound cries of injustice, human rights discourse would simply be inappropriate. Only the spirit of truth, justice and love can offer any meaningful appeasement. Although the section 'Revisiting Nigeria' in the present article considers how Weil suggested this could be achieved, her criticisms of human rights would certainly invite objections. Some might point to specific contemporary and historic instances in which human rights have been instrumental in offering substantive appeasement, such as the recognition of the suffering of slaves, women, indigenous peoples and political prisoners. At the same time, there are equally numerous contemporary and historic forms of human suffering that human rights fail to recognise. The inhospitality to millions of refugees and asylum seekers across the world today, the inexcusable levels of global poverty, the violence of development (Rajagopal 2003, p. 197), the widespread discrimination of people with disabilities, and the hierarchy given to human rights violations in war time over violations in peace time (Baxi 2002) all vindicate Weil's thesis on the ethical blindness of human rights. Her insights on the commercial nature of human rights claims are also evident from the way in which they have surreptitiously been used to further corporate interests to the extent that their malleability, to borrow Baxi's (2002, p. 132) terminology, has given rise to a trade-related market-friendly paradigm. Although it might be tempting to interpret Weil's criticisms as a critique of human rights in pointing out precisely how to remedy their ethical blind spots, it is equally important to explore the ways in which her criticisms, together with other aspects of her writings, can inspire new ethico-political practices capable of recognising and responding to discrete forms of human suffering. To appreciate the need for alternatives, and how Weil's work may inspire a particular alternative, in the next section I explain the problems of the international human rights system that account for the failure to implement the Convention in Nigeria.

\section{Disability Human Rights in Nigeria}

Along with the millions of disabled persons around the world, an estimated 19 million Nigerians (Cornelsen 2012, p. 3) with a variety of disabilities rely on the promise of the Convention, not only to guarantee their human rights, but also to counter the exclusions and injustices of their national legal system. The potential of the Convention, as with the international human rights system in general, is paradoxically contingent on the degree to which the human rights of persons with disability are effectively protected and enforced in the national legal system. A well- 
known and general problem with the protection of human rights is the inability to replicate domestic enforcement mechanisms in the international sphere. Traditional notions of state sovereignty remain resilient, and formidable barriers against achieving universal human rights because an effective international enforcement of human rights has never really materialised. Part of the problem is the lack of agreement or clarity on what international enforcement means. Enforcement means different things, ranging from the use of, or threat of the use of, moderate or extreme armed force, to economic or other types of sanctions, as well as other coercive measures and forms of persuasion (Alston and Goodman 2013, pp. 689-690). Indeed, at the global level, and to a large extent locally, moral persuasion by nongovernmental organisations (NGOs), the media and human rights activists is still a powerful and effective tool for enforcing human rights. It is arguably the power of morality and not the effectiveness of the international legal enforcement system that explains why the struggles for disability justice in Nigeria, and across the globe, are now exclusively carried out in reference to human rights.

The views above are by no means universal. The significance of the Convention, which formally came into force on 3 May 2008, is located in its potential for legal enforcement (Stein and Lord 2008) rather than the moral weight of human rights. Although persons with disability generally could rely on protections afforded by the core international human rights treaties, the Convention and its Optional Protocol is novel for introducing justiciable disability human rights. The emergence of the Convention, which culminated years of activism by the global disability movement (Meekosha and Soldatic 2011, p. 1386), now potentially offers protection to an estimated one billion people who live with disability (World Health Organization 2011, p. xi). The Convention is notable for breaking the hold of medical perceptions of and approaches to disability by moving discourse in this context to the social model. The Convention is currently made up of 185 state parties, 85 of which are signatories to the Optional Protocol. The Convention refers to persons with disabilities as 'those who have long-term physical, mental, intellectual or sensory impairments' (Article 1) that obstruct equal participation in society and contains 47 comprehensive provisions collectively seeking 'to promote, protect and ensure the full and equal enjoyment of all human rights and fundamental freedoms by persons with disabilities, and to promote respect for their inherent dignity' (Article 1).

The Convention is founded on the 'respect for inherent dignity, individual autonomy including the freedom to make one's own choices, and independence of persons' (Article 3a) as one of its eight general principles. Other principles include non-discrimination; full and effective participation and inclusion in society; respect for difference; equality of opportunity; accessibility; equality between men and women; and respect for the evolving capacities and rights of children with disabilities (Article 3). Apart from dispelling questions about the individual basis of the Convention, autonomy together with the freedom of choice and independence as general principles are unmistakably an attempt to assert the equality of persons with disabilities with all human beings as well as to distance itself from charitable perceptions and approaches to disability justice. It is understandable why the Convention seeks to move away from charitable approaches (Hammarberg 2011, p. 641), especially because of the paternalism, among other things, it often invites. 
However, the Convention, if looked at through Weil's lens, seems too quick to distance itself from charity. Apart from a seemingly obvious misinterpretation of the complex and multidimensional nature of responses to the complexity of disability itself, the Convention, in seeking to assert the equality of persons with disabilities through Kantian-like notions of autonomy (Megret 2008, pp. 510-514), fails to appreciate the value of human interdependence as a significant aspect of the quality of human life. The richness of human life is not defined by the ability to live autonomously, but rather it is defined by the human interrelationships that are pivotal for self-growth, development and flourishing. Nevertheless, there is something to be said about its novel articulation of 'the equal right of all persons with disability to live in the community' (Article 19), which, at face value, seems appreciative of the value of community and human interdependence. However, this appears to be undermined by the overall emphasis on individual autonomy (Parker and Clements 2008) within community.

The Convention does not create new human rights per se, but rather it applies, reformulates and extends existing human rights norms to take into account issues specific to persons with disability in ways that recognise their equality with all human beings (Megret 2008, p. 500). This is evident in its attempt to strike a balance between, on the one hand, civil and political rights (Articles 12-29) and, on the other hand, economic, social and cultural rights (Articles 24-28). Apart from a precise list of state obligations that require state parties to either create, modify or abolish laws, regulations, customs and administrative practices (Article 4a-i), the Convention is complemented by international monitoring and implementation procedures (Articles 31-40). The Committee on the Rights of Persons with Disabilities ('the Committee') is given the mandate by the Convention to receive state reports and shadow reports from disabled persons' organisations and other interest groups. Indeed, the participation of disabled persons' organisations is integral to the process of monitoring and implementation, which was specifically designed to largely represent people with disabilities. The Committee has the power to issue general comments and recommendations and to transmit biennial reports to the General Assembly of the United Nations. The Committee can also receive individual and group complaints or communications regarding alleged violations of provisions of the Convention. The Committee consults on and assesses various issues relating to implementation of the Convention through specialised United Nations agencies and the conference of state parties (Article 40) respectively.

Nigeria signed the Convention and its Optional Protocol on 30 March 2007 (the first day they both opened for signature) and ratified both on 24 September 2010. Nigeria joined 16 other African countries (Stein and Lord 2013, p. 98) in signing the Convention on the first day it opened for signature. Similarly, Nigeria is one of 18 African state parties to the Optional Protocol, which by implication means that the country has voluntarily submitted itself to the oversight functions of the Committee. Nigeria, among other African state representatives, has also contributed to operationalising the Convention, and Nigeria currently has an expert who sits as an elected member of the Committee. Although Nigeria has not submitted its state party report on the measures it has taken to fulfil its obligations under the Convention (Article 35), it actively takes part in the conference of state parties. 
Nigeria joined a host of African states that have not only enthusiastically contributed to and embraced the Convention, but have also paradoxically failed to implement it in terms of legislation, policy and programmes. The disparity between this international display of acceptance, in the light of the level of African participation, and the implementation of the Convention is bewildering. This observation is particularly salient with Nigeria, which continues to demonstrate support for the Convention publicly and at international fora, but has not followed through this support with concrete implementation measures. Thanks to the initiative of the Nigerian disability movement (which I return to in the section 'Revisiting Nigeria'), a disability bill was drafted in 2007 and was successfully debated before the floor of the Nigerian Parliament the subsequent year. However, it has not yet received the presidential assent to transform it into law. Could the indifference of the Nigerian authorities be a vindication of Weil's objections to human rights discourse, or could there be an alternative explanation? Before any conclusion can be drawn, it will be helpful to turn to the most common explanations of the disparity between international human rights treaty ratification and domestic implementation, and possible ways to overcome it.

\section{Internalising Human Rights Norms}

A comprehensive explanation for the disparity between Nigeria's ratification of the Convention and the lack of domestic implementation firstly depends on a wider enquiry into Nigeria's general attitude to its international human rights obligations. Nigeria's record is impressive: it has signed and ratified all the core international human rights treaties and their Optional Protocols. Out of these, Nigeria has implemented only the United Nations Convention on the Rights of the Child through domestic legislation, even though this has not been without controversy and is an indication of its poor record of implementation. Although Nigeria's generally poor record of implementing international treaties partially explains why it has failed to implement the Convention, other factors may be responsible in the light of the poor record of the international human rights law system on monitoring and enforcement. Ideally, state accession to international human rights treaties and their Optional Protocols not only should have a trickle-down effect, but ought to serve as a catalyst for social change on the domestic level. When states implement their international obligations through legislation, policies and programming, a culture of compliance is nurtured, diffusing human rights norms to walks of life in a particular political community. Legislation importantly makes the human rights in question justiciable in courts of law, thereby placing the responsibility for enforcement on the judiciary.

In the light of the problems of the international enforcement of human rights, certain scholars have offered alternative explanations and remedies to the disparity between international human rights law treaty commitments and domestic implementation in international relations and international legal theory, even though my discussions here focus on the latter and not the former. Two approaches-Goodman and Jinks's (2004, 2008, 2013) theory of acculturation 
and Koh's $(1996,1997,1998,2004)$ transnational legal process theory-stand out in this respect, as they explain reasons for the disparity between treaty ratification and domestic implementation as being not necessarily the weakness of international enforcement mechanism but the failure of states to internalise those treaty norms. Although these issues have historically been addressed by Chayes and Chayes's (1998) 'managerial model', consent-based theories inspired by the timeless writings of Henkin (1979) and theories of legitimacy (Franck 1998), to mention a few, these theories have only, in the light of their primary focus on compliance (Raustiala and Slaughter 2001, p. 538), tangentially dealt with this issue as a question of how doctrines and norms, including human rights norms, are or are not internalised by states' agents.

In response to this, Goodman and Jinks, and Koh offer unique perspectives on how to overcome this problem. According to Goodman and Jinks, compliance to international treaty norms by states is contingent on an acculturation, which is a form of socialisation. Acculturation is achieved when pressure is exerted on a particular state, and the state's officials not only identify with but also conform to the cognitive frames and behavioural expectations of the particular international legal regime. Koh's transnational legal process theory, which is offered as both a theory of explanation and a blueprint for internalising international norms in practice (Koh 2004, p. 344), is arguably the most sophisticated approach and comes close to addressing the anxieties raised in the preceding paragraph. Described as a non-traditional (hybrid between domestic and international or public and private law), nonstatist (state and non-state), dynamic (top-down and bottom-up) and normative (value oriented) transnational legal process (p. 184), Koh defines it as a 'theory and practice of how public and private actors...interact in a variety of public and private, domestic and international fora to make, interpret, enforce, and ultimately, internalize rules of transnational law' (Koh 1996, pp. 183-184).

Although important, acculturation and transnational legal process theory are unable to explain why Nigeria's impressive level of engagement with the international human rights system has not replicated those norms in its domestic system. Moreover, both approaches do little to move away from the scholarly treatment of human rights as formal and state-centric constructs, which are not only structured hierarchically, but also as products of top-down international juridical mechanisms. For instance, the problem with acculturation is not only its top-down formal nature, but also that it is not primarily concerned with accepting the ethical or moral validity, legitimacy and beliefs of human rights norms; it is only interested in these to the extent that they conform to the needs of the social structure or organisational environment (Goodman and Jinks 2004, p. 643). After all, acculturation entails 'outward conformity with a social convention without private acceptance' (2004, p. 643). Although acculturation may support treaty compliance, without the rational acceptance of the treaty norms themselves, it ultimately falls short of demonstrating how international human rights norms are actually internalised. I do not dismiss the possibility of implementing, enforcing or complying with a human rights treaty norm without actually internalising those norms, but it is difficult to understand how this can be effective or sustained in the 
long term without being enmeshed in the nature of that norm itself, or what constitutes a violation of it.

To be fair, Koh's work moves the debate on internalising international norms beyond its traditional state-centric focus, but it does not show how those norms are actually internalised independent of international juridical structures. Koh's transnational legal process approach appears successful only if it is supported by transnational or domestic adjudicatory processes, especially the European Court of Human Rights, which Koh relies upon to validate his thesis (Koh 1996, pp. 670-674). Although his thesis recognises NGOs and other interest groups, which may include disabled persons organisations, as potential transnational norm entrepreneurs, it is unclear how the processes initiated by these groups lead to the internalisation of international human rights norms except through the already discredited or ineffective international enforcement system. In the case of Nigeria, as has been demonstrated in the section 'Disability Human Rights in Nigeria', it has actively been involved in various transnational disability human rights processes, but this has led neither to internalisation of the Convention nor to domestic implementation. Transnational legal process theory, as with acculturation, apart from taking human rights as a given, ends up reinforcing international human rights norms as formal, state-centric and top-down juridical constructs, which elide the possibility of properly appreciating the ability of human rights norms to foster the capacity of state agents to respond to human rights violations.

To return to Weil, the problem with human rights is more fundamental than being able to internalise them. Even if it were possible to internalise human rights norms, this is no guarantee for disability justice. This is specifically because human rights, as Weil has eloquently educated us, suffer from an 'intrinsic inadequacy' (Weil 2005 , p. 71), which prevents them from living up to their most fundamental of functions, namely, to ameliorate human suffering. Although state agents may absorb or assimilate international human rights norms, principles, beliefs and values, not only in ways that they become part of their personal and institutional features, those norms, principles, beliefs and values cannot foster the human capacity to empathise with or care for others. After all, to return to Weil's insights, our responses to human rights violations are contingent not only on the creation of institutional enforcement structures, but also on being able to recognise and empathise with those whose rights are being denied or violated altogether. It may be unfair to judge acculturation or transnational legal process theory on the standards established by Weil, because they not only have different starting points, but also different objectives. The problem, however, is that both acculturation and transnational legal process theory take human rights as a given, which Weil does not. It is precisely because of their inability to vividly express cries of injustice that Weil objects to the juridification of human rights. More fundamentally, Weil's thesis questions the ability of human rights texts and instruments to effectively guide just decision-making and moral behaviour. The difficulty with reasoning that is based on human rights is that it does not clearly prohibit unjust decision-making and undesirable behaviour. Human rights-based reasoning cannot effectively be relied upon by the bearer of a human right, by the judge in a human rights legal dispute or by the member of an international human rights treaty monitoring committee to reach the morally correct 
or just decision. Partly responsible for this, we may recall, is the denial of 'the impulse of charity' (Weil 2005, p. 83) between parties or an adjudicator of a human rights dispute. The emotional distance or detachment anticipated of parties or an adjudicator of human rights dispute is particularly the greatest obstacle to the ability to empathise with or care for a person whose human rights have been violated. To explore how Weil may inspire a different alternative, it is now helpful to return to the Nigerian context.

\section{Revisiting Nigeria: Disability Justice Beyond Human Rights?}

It was called the 'one-day disability experience' (Okoli 2012), an event organised by organisations representing persons with disabilities in Nigeria, one aim of which was to present a draft legislation on the rights of persons with disabilities to the Nigerian law-makers. However, it was unlike most formal ceremonies of this nature because the organisers of the event took the opportunity to provide the legislators with a lived experience, albeit for one day, of what it means to live as a disabled person. Many legislators had their ears blocked, mouths gagged and eyes blindfolded, while others experienced the use of wheelchairs for the whole day. Although an in-depth study into the full ramifications of the event, including what it achieved or failed to achieve, has not been carried out, that experience must have had a dramatic effect on the legislators, because they unreservedly and promptly guaranteed the speedy passage of the Nigerian disability bill. The legislators' comportment may have been influenced by their concrete encounter, even though it was temporal, with the nature and some of the possible consequences of disability. It must surely have given some legislators personal insights into the types of physical, psychological and social barriers that individuals with disabilities encounter daily in some specific public environments. Without doubt, some legislators may have experienced some vulnerability in realising that they could experience a disability at some point in life, either temporarily or permanently. The legislators certainly would not have exhaustively appreciated the condition of the disabled, just as there is a distinction that can be drawn between appreciating what it means to live with a disability from birth and what it means to live with a disability from early childhood, adolescence or adulthood. However, in spite of the surely purgative experience for the legislators, the responsibility for transforming the bill into law is not exclusively theirs. Much hangs on the Nigerian president's power of assent, which, for unknown reasons, has not as yet been forthcoming. A two-thirds majority of the Nigerian Parliament can override the need for presidential assent after 30 days if they reasonably believe it is being unfairly withheld (Mbaya et al. 2013, p. 113). Unfortunately, though, Nigeria's law-makers seem to have other priorities, because they have not been radical enough to utilise this option.

It is difficult to describe the one-day disability experience as a successful event, in the light of the protracted nature of the disability bill. However, that it was able to galvanise law-makers to pass unreservedly the bill is some indication of its relative success and to some extent of its potentially effective nature as a strategy for disability justice. To understand this argument, I begin with a discussion in an 
attempt to make sense in conceptual terms of what the one-day experience exactly is, why it may have had this radical impact, its potential for the future (i.e. how it may be diffused to members of society), its possible weaknesses, and how some of these may be overcome by aligning it with insights from Weil. To many disability rights activists, academics and practitioners, the one-day disability experience was simply a disability simulation exercise, which sought to cognitively induce changes in attitudes and prejudices towards people with disability (Kiger 1992; Flower et al. 2007). Although the relatively small body of literature in this area implies that there are doubts about their effectiveness (Silverman et al. 2015; French 1992), disability simulations have as their primary objective the amplification of individual perceptual sensitivities, particularly the ability to empathise with and adopt positive attitudes towards persons with disabilities (Kiger 1992, p. 73). While the range of activities may vary, disability simulations practically involve the use of wheelchairs and earplugs or being immobilised in some way, or blind walks or being fed by another person. The premise behind such simulations is that loss of sight, hearing or mobility, even if it were on a temporary basis, would provide a phenomenological experience of disability, which in turn would help participants empathise with the human condition of persons with disabilities (1992, p. 73). Simulations can potentially reduce individual prejudice among the participants, which can subsequently be translated to the reduction of societal prejudice.

In spite of the positive impact that disability simulations can have, there are doubts, for three general reasons, about their overall effectiveness in the light of their objectives. First, there is the lack of comprehensive empirical research on the social-psychological impact of disability simulation exercises on participants (Silverman et al. 2015). Second, there is evidence that disability simulation exercises can impact negatively on participants. Apart from falsely or erroneously depicting persons with disabilities (French 1992, p. 257), simulations have encouraged disparaging perceptions of disabled persons as objects of pity or subordinate, diffident and feeble people (Kiger 1992, p. 72). Thirdly, and more importantly, apart from being difficult if not impossible to simulate certain types of disabilities, these simulations, especially because of their ad-hoc nature, do not comprehensively lead to a realistic depiction or phenomenological experience of disability. Some studies (Silverman et al. 2015, p. 465) have discovered that simulation exercises provide false and misleading information about persons with disabilities, including values prized by the disability movement, such as the ability to live independently.

Disability simulations can be inappropriate. There is no point in using simulations if they are or are likely to be counter-productive, although some of their limitations can be overcome by adopting precautionary measures. However, it does not appear that the participants of the one-day disability experience in Nigeria, possibly because it lasted for only one day, were challenged by the problems listed above. On the contrary, the one-day disability experience did seem to have a positive impact in terms of the rapidity with which the protracted Nigerian disability bill was promptly and unanimously agreed by the Nigerian Parliament. For this reason $\mathrm{I}$ argue, even if it is based on an intuition, that more meaningful changes to the plight of persons with disabilities might have occurred if disability simulations 
had been pursued further and among a wider spectrum of the Nigerian society. Indeed, even though this is not my argument, simulations can generally achieve an impact beyond the question of disability. Simulations can help address other societal problems, including violations of human rights, such as discrimination, torture and unlawful detention. A simulated experience of discrimination or torture is likely to alter a moral agent's perception or capacity to empathise with those whose human rights have been violated.

The limitations of disability simulations noted above may be an indication of the need to have realistic expectations, and perhaps to see them as part, and not independent, of a wider legal and political framework for securing disability justice. To manage high expectations, it is better to think of disability simulations as an instrument that can serve as a catalyst for a wide range of activities, including laws, policies and programmes that contribute to reduction of prejudice on a societal scale. Disability simulations can achieve this if they are designed in ways that take some of the limitations noted above into account, with a view to using the tool regularly and widening the range of participants to lead to a wider societal appreciation of the predicaments encountered by persons with disabilities. It is also important to consider the idea of setting aside one day or more a year to encourage all Nigerians in all walks of life to take part in some sort of disability simulation activity. The frequent and wider societal use of disability simulations is critical to providing precisely the sort of praxis that can guard against the complacency often assumed that new laws or inclusive political and legal institutions are the definitive end of disability justice. With regular engagement in disability simulations, Nigerians have a mechanism that will always remind them that the creation of new laws and institutions is only the means and not the end in itself.

The justification for disability simulations is contingent on appreciating how they may be elevated to a higher level of ethical and political significance than is currently the case, and how this may yield better appreciation of human obligations. In disability simulation activities, Nigerians can arrive at the type of praxis that comes close to replicating what Weil defined as attention: an ethical process through which individuals can actively and passively experience and 'care' (Dietz 1988, p. 97) for those in need. Through the concept of attention, disability simulations can be reconstituted into an intrinsic participatory process that offers the potential not only to enhance the human capacity to cognitively grasp or respond to human suffering, but also to take part in that suffering. To appreciate this, it will be helpful to consider what attention means in more detail.

The concept of attention features prominently in several essays by Weil, but it is in her essay Reflections on the Right to Use School Studies with a View to the Love of God (Weil 2009) that it is given its most detailed treatment. In that essay, Weil proposed attention as a pedagogical device, but it has multiple connotations, including a remedy for force (Weil 2005, pp. 182-214), power, a form of prayer (Weil 2009, p. 57) and a form of love (Weil 2005, p. 92), that is, a means to love God and one's neighbour. Although it is difficult to disentangle various connotations of attention from each other, its significance of how one comes to love one's neighbour is relevant for present purposes. In relation to this, attention, the suspension of the 'thought, leaving it detached, empty, and ready to be penetrated 
by the object' (2009, p. 63) is ultimately a form of justice (Winch 1989, pp. 179-190; Bell 1998, pp. 47-54), a means to literally see that 'no harm is done' (Weil 2005, p. 93) to one's neighbour. Attention can be achieved only if 'the soul empties itself of all its own contents in order to receive into itself the being it is looking at, just as he is, in all his truth' $(2009$, p. 65). Attention, as such, enables the

recognition that the sufferer exists, not only as a unit in a collection, or a specimen from the social category labeled 'unfortunate', but as a man, exactly like us, who was one day stamped with a special mark by affliction. For this reason it is enough, but it is indispensable, to know how to look at him in a certain way. This way of looking is first of all attentive. (2009, pp. 64-65)

Weil's objections to the language of personalism are again obvious from this passage. By recognising the sufferer only through a certain type of category- " "the poor", "the unemployed", "the needy" (Dietz 1988, p. 128) or even the disabledthe sufferer is not only stereotyped, but also consigned to obscurity. Weil has another reason for objecting to categorising the sufferer. She says that it enables the non-afflicted to develop an emotional distance from the afflicted either to deny, falsify or make the afflicted's condition tolerable (1988, p. 128). This can be avoided, and real attention achieved, only if the non-afflicted takes part in the suffering of the afflicted. The non-afflicted must avoid any distance from the afflicted so as to avoid being overcome by prejudice or 'self-regarding motives' (1988, p. 129) such as personal esteem, pity or the motivation for eternal salvation. Unlike Kant, whose work gave primacy to the impartiality and distance of a moral agent as a hallmark of superiority, Weil argues to the contrary. She argues that our ability to address deep cries of human suffering depends not on assuming distance between the non-afflicted and the afflicted, but rather it depends on the ability of the former to participate in the suffering of the latter. The full appreciation of the rational dignity of the afflicted can be achieved only if the non-afflicted is wholly enmeshed in union with the afflicted and furthermore with the source of affliction. This cannot be achieved from a distance by impartially alleviating the afflicted. This is vulnerable to abuse, paternalism or the dehumanisation of the object of attention. This is precisely what, as Bankowski (2013) eloquently tells us, makes Weil both original and radically different from Martha Nussbaum's (2006, pp. 156-222) approach to disability justice among others:

[T] hey do not embrace the disabled; rather, they want to make the disabled like themselves - they have a cool rationality, albeit full of compassion; their religion is Kant. They are not mutual partners in vulnerability and suffering but they are there to help from their superior position. In doing it this way, however, they cannot see. They 'feel the other's pain' but have none of their own. (Bankowski 2013, p. 313)

Weil would not deny that moral agency cannot be realised independently of detachment; however, for her, unlike Kant, such detachment that yields respect for the dignity of the afflicted cannot be achieved transcendentally, but immanently (Dietz 1988, p. 130). This is partly why she objects to human personality, because it presumes the separation between the non-afflicted and the afflicted. Attention is not 
only original in this respect, but it also presumes a radical form of equality between the non-afflicted and the afflicted of the kind uncommon to human rights discourse. This makes attention difficult to achieve. Even Weil acknowledged that attention was not symptomatic of common human behaviour.

Although attention may be difficult, Weil also suggests that it is not impossible. Every human being, regardless of his or her situation in life, is capable of the power of attention and love. This, however, depends on practice because attention is realisable by those who consent to it only if it is cultivated. Attention is, therefore, a means by which human obligations are literally implemented. To begin to see how attention can revitalise the practice of disability simulations generally and in Nigeria particularly, it is sensible to conclude this section by considering what Weil means by obligations, to understand their inexplicable link to attention, and why they, not human rights, should assume primacy in the debate about disability justice. Obligations are eternal, Weil says, and they always have priority over rights. Human rights are not only subordinate, but cannot exist or be effective without obligations. A human right that is not recognised ceases to exist, whereas an obligation continues to exist. She explains this with yet another analogy: '[A] man left alone in the universe would have no rights whatever, but he would have obligations' (Weil 2002 , p. 4). Weil means that rights are always dependent on obligations, whereas obligations enjoy an existence outside conditions. Obligations are binding on all human beings in an identical way, even though they may be exercised differently and in different circumstances. Obligations are unconditional: human beings have an obligation to other human beings on the basis of nothing else than their humanity. As such, obligations are ultimately 'not based on any de facto situation, nor jurisprudence, custom, social structure...' (2002, p. 5) or 'convention' (2002, p. 5).

Obligations are permanent, and they cannot be nullified except in the case of the existence of two sincere and incompatible obligations (2002, p. 4). Men and women in positions of authority have a higher standard of obligations of the kind that amounts to a criminal offence if they are not fulfilled. Obligations are equally matched to and respond to human needs (Weil 2005, p. 224). Human beings are under obligations not to violate or reject the needs of other human beings. Such an obligation cannot be subordinated by other considerations except necessity or the needs of other human beings. As Weil says, if the obligation to ameliorate a human need is violated, the violated will 'fall little by little into a state more or less resembling death, more or less akin to a purely vegetative existence' (Weil 2002, p. 7). If Weil's overall thesis is that attention is 'an act through which the unafflicted "project their being" into the afflicted' (Dietz 1988, p. 129), then it can supply exactly the kind of obligations that currently elide disability human rights discourse.

Weil's concept of attention, particularly the primacy it gives to human obligations, can influence disability simulation exercises in at least three related ways. First, at a basic level, it would help to elevate disability simulation exercises to intrinsic participatory processes that would radically affirm the equality of all participants: disabled and non-disabled. Weil argued that the ability to cognitively recognise and respond to human suffering depends not on assuming distance between the non-afflicted and afflicted, but rather on the unity of the former and latter. Our perceptive awareness or empathy for others can be enriched or amplified 
only if we directly take part in their privations. There is, of course, a question mark about whether we can actually or completely achieve this, especially through simulation exercises. Notwithstanding, I believe that simulation exercises, unlike formal juridical processes, provide the closest approximate experience of what it is like to live with a disability. Attention can elevate disability simulations to a level of ethico-political significance, in the sense that it can offer the much needed critical space for participants to pause and recognise the limitations of their convictions, ways of thinking, perceiving, communicating and acting. It can provide participants with the standard of vigilance and receptiveness to particularity through 'rupture and refreshment' (Del Mar and Onazi 2009, p. 353) and 'defamiliarisation and estrangement' (2009, p. 353). Without doubt, attention is difficult to achieve in the literal sense, not only because it requires individuals to confront their innate prejudices, but also because it entails a kind of openness to vulnerability or to the possibility of being hurt or wrong about one's convictions. Attention is the equivalent of a process of rebirth conterminous with 'learning to speak and see and act anew' (2009, p. 353). Attention may be difficult, but it is not impossible. We all have within our midst the power to achieve attention when we consent to it. In other words, attention is itself dependent on precisely the kind of aptitude that it seeks to encourage: it is only by exercising it that we can achieve it; practice, therefore, is indispensable.

Second, because attention entails a unique process of 'participatory detachment', whereby moral agents are encouraged to suspend their thought, to leave it 'empty, and ready to be penetrated by the object' (Weil 2009, p. 63), the ability to cultivate such an aptitude can provide an antidote to negative perceptions and effects that accompany disability simulation exercises. The ability to overcome the limitations of disability simulation exercises is contingent on a proper understanding of Weil's main reasons for proposing attention as a means of recognising human suffering and vulnerability. It begins from appreciating how uncharacteristic it is to assist the afflicted to the extent that those who think they possess this attribute are often misguided (Dietz 1988, p. 126). It is much easier to detest, deny or simply misunderstand the human condition of the afflicted. It is even more difficult for moral agents to situate themselves in the human condition of the afflicted. It is only the love of the neighbour (as opposed to graciousness, pity and precipitateness) that can bring the moral agent as close as possible to appreciating the condition of the afflicted. Weil is suggesting that attention can be either true or false depending on the attitude or intention of the non-afflicted. The intention behind the act of attention is equivalent to the act of attention itself. True attention is achieved through a certain kind of openness to the afflicted that does not seek to make the affliction tolerable. Apart from radically affirming the equality of the disabled and nondisabled person, attention cannot be genuine if it is concealed by other motivations, especially power or self-esteem. Attention is only genuine if it is a sincere response to a cry of injustice. False attention, on the other hand, takes a variety of forms, ranging from impulsively, infrequently or frequently helping the afflicted through routine, indoctrination, social custom, pretentiousness, pity, moral virtue or personal gratification (Weil 2009, p. 127). True attention entails the recognition of and concern for the afflicted in their real or particular circumstances. For this reason, 
and to achieve the reflective tranquillity that is required to puncture the most obscure or obvious forms of affliction, true attention is possible only when the nonafflicted takes active part in the suffering of the afflicted. It is this attribute that equips attention with qualities that can elevate disability simulation exercises to authentic and radical transformative processes. Attention can help to transform disability simulation exercises not only into a platform for achieving authentic lived disability experiences, but also into a practical mechanism for avoiding erroneous and disparaging perceptions of disabled persons as mere objects of pity.

The third point is not necessarily a problem with or a response to a problem with disability simulation exercises. Rather, it is to demonstrate that such exercises may offer an alternative approach to disability justice that radically breaks from the international human rights system particularly (as illustrated in the analysis in the sections 'Disability Human Rights in Nigeria' and 'Internalising Human Rights Norms') with its weak enforcement mechanisms and opportunities to internalise human rights norms. Instead of relying on human rights discourse as a frame of reference for disability simulation exercises, the latter must be appreciated as either a challenge to or an alternative to the former. Although some readers may find Weil's criticisms of human rights objectionable, her writings can be relied upon to ground an alternative conception for justice. Unlike contemporary theories of justice, which take the kind of treatment owed to citizens of a given society as their starting point, Weil starts from the opposite perspective by emphasising how citizens should treat other citizens, especially the most vulnerable in society. By her emphasis on human obligations as the constitutive element of justice, Weil particularly speaks to the powerful or those in already recognised, secure or privileged positions. In doing so, Weil succeeds in shifting the focus of attention from the object to the subject of human obligations. Apart from encouraging us how to think or act justly, independent of human rights, Weil's notion of justice (to see that no harm is done to others) is both an absolute and a transcendental human obligation to other human beings on the basis of love and compassion. It is hardly debatable that contemporary theories of justice take for granted the significance of human obligations. Nowhere is this more apparent than in disability justice discourse, which is almost exclusively framed in terms of the human rights of persons with disability. Little, if anything, is said about the human obligations owed to persons with disability. Weil's notion of justice, therefore, can significantly contribute to disability justice discourse by underscoring the need to move beyond extending equal standards of human rights to persons with disabilities to bring to attention the requirements of disability justice by way of human obligations. Nevertheless, it would be naïve to suggest that human rights have no contribution to make to disability justice, especially in the light of their widespread dominance among other things. Instead, I suggest the need to take the search for alternatives more seriously. This is perhaps the strongest message in Weil's essay; it provides the much needed inspiration to escape the monopoly of the way of seeing, thinking and acting through human rights. 


\section{Conclusion}

In this article, I have pointed out some salient features of Weil's criticisms of human rights and argued that they provide an alternative explanation for the disparity between Nigeria's international commitments and domestic implementation of the United Nations Convention on the Rights of Persons with Disabilities. While the human rights literature on social change treats this as a problem of internalising human rights norms, the conclusions that can be drawn from Weil's writings suggest that the problem is more fundamental than what appears in the literature. For Weil, the problem is intrinsic to human rights. The indifference of Nigerian authorities to the Convention can be explained by the inability of human rights to serve as an action-guiding principle that can cause the powerful to empathise with various forms of human suffering and vulnerability. I have argued that if Weil's criticisms of human rights are read together with her concept of attention, an alternative framework for disability justice can be achieved. I have shown this by arguing that Weil's concept of attention confers a capacity for obligations of a kind unknown to human rights discourse and it can in turn help to refine and reconstitute disability simulation exercises into a vehicle for an alternative disability justice.

Acknowledgments I would like to thank the Independent Social Research Foundation (ISRF) for the generous funding that has enabled me to complete this article, partly connected to a study on disability justice in Africa. An earlier version of this article was presented at a Special Working Group of the XXVII World Congress of the International Association for the Philosophy of Law and Social Philosophy (IVR), Georgetown Law Center, 2015.

Open Access This article is distributed under the terms of the Creative Commons Attribution 4.0 International License (http://creativecommons.org/licenses/by/4.0/), which permits unrestricted use, distribution, and reproduction in any medium, provided you give appropriate credit to the original author(s) and the source, provide a link to the Creative Commons license, and indicate if changes were made.

\section{References}

Alston, Philip, and Ryan Goodman. 2013. International human rights. Cambridge: Cambridge University Press.

American Anthropological Association (Executive Board). 1947. Statement on human rights. American Anthropologist 49(4): 539-543.

Bankowski, Zenon. 2013. The long goodbye: a ... life in and out of the law. In The anxiety of the jurist: Legality, exchange and judgement, ed. Maksymilian Del Mar, and Claudio Michelon, 299-316. Surrey: Ashgate Publishing Limited.

Baxi, Upendra. 2002. The future of human rights. New Delhi: Cambridge University Press.

Bell, Richard. 1998. Simone Weil: The way of justice as compassion. Lanham: Rowman \& Littlefield Publishers Inc.

Bentham, Jeremy. 1987. Anarchical fallacies. In Nonsense upon stilts, ed. J. Waldron, 46-69. London: Methuen.

Chayes, Abram, and Antonia Chayes. 1998. The new sovereignty of compliance with international regulatory agreements. Cambridge, MA: Harvard University Press.

Cornelsen, Kathleen. 2012. Reports on the situation of disabled persons in Nigeria. Washington, DC: Global Rights: Partners for Justice. 
Del Mar, Maksymilian, and Oche Onazi. 2009. The moral quality of work: Resisting complacency. International Journal of Law in Context 4(4): 337-372.

Dietz, Mary. 1988. Between the human and the divine: The political thought of Simone Weil. New Jersey: Rowman \& Littlefield Publishers Inc.

Douzinas, Costas. 2000. The end of human rights. Oxford: Hart Publishing.

Engle, Karen. 2001. From skepticism to embrace. Human rights and the American Anthropological Association from 1947-1999. Human Rights Quarterly 23(3): 536-559.

Flower, Ashley, Matthew K. Burns, and Nicole A. Bottsford-Miller. 2007. Meta-analysis of disability simulation research. Remedial and Special Education 28(2): 72-79.

Franck, Thomas. 1998. Fairness in international law and institutions. Oxford: Oxford University Press.

French, Sally. 1992. Simulation exercises in disability awareness training: A critique. Disability, Handicap and Society 7(3): 257-266.

Goodman, Ryan, and Derek Jinks. 2004. How to influence states: Socialization and international human rights law. Duke Law Review 54(3): 622-703.

Goodman, Ryan, and Derek Jinks. 2008. Incomplete internalization and compliance with human rights law. The European Journal of International Law 19(4): 725-748.

Goodman, Ryan, and Derek Jinks. 2013. Socializing states: Promoting human rights through international law. Oxford: Oxford University Press.

Hammarberg, Thomas. 2011. Disability rights: From charity to equality. European Human Rights Law Review 6: 638-641.

Henkin, Lewis. 1979. How states behave: Law and foreign policy. New York: Columbia University Press.

Kiger, Gary. 1992. Disability simulations: Logical, methodological and ethical issues. Disability, Handicap and Society 7(1): 71-78.

Koh, Harold. 1996. Transnational legal process. Nebraska Law Review 75: 181-207.

Koh, Harold. 1997. Why do nations obey international law? Yale Law Journal 106: 2599-2659.

Koh, Harold. 1998. Bringing international law home. Houston Law Review 35: 623-681.

Koh, Harold. 2004. Transnational legal process after September 11th. Berkeley Journal of International Law 22(3): 337-354.

Marx, Karl. 2007. On the Jewish question. In Marx: Early political writings, ed. J. O'Malley, 28-56. Cambridge: Cambridge University Press.

Mbaya, Paul, Charas Madu Tella, and Raphael Audu Adole. 2013. The processes of law making in a presidential system of government: The Nigerian experience. Asian Social Science 9(2): 106-114.

Meekosha, Helen, and Karen Soldatic. 2011. Human rights and the global south: The case of disability. The World Quarterly 32(8): 1383-1398.

Megret, Frederic. 2008. The disabilities convention: Human rights of persons with disabilities or disability rights? Human Rights Quarterly 30: 494-516.

Nickel, James. 2005. Poverty and rights. Philosophical Quarterly 55(220): 385-402.

Nussbaum, Martha. 2006. Frontiers of justice: Disability, nationality and species membership. Cambridge, MA: Harvard University Press.

Okoli, Cosmas. 2012. Racing towards the rights of persons with disabilities in Nigeria. Huffington Post. http://www.huffingtonpost.com/cosmas-i-b-okoli/racing-towards-rights-for_b_1499400.html. Accessed 25 June 2015.

Onazi, Oche. 2013. Human rights from community: A rights-based approach to development. Edinburgh: Edinburgh University Press.

Parker, Camilla, and Luke Clements. 2008. United Nations Convention on the Rights of Persons with Disabilities: A new right to independent living? European Rights Law Review 4: 508-523.

Rajagopal, Balakrishan. 2003. International law from below: Development, social movements and third world resistance. Cambridge, MA: Cambridge University Press.

Raustiala, Ka, and Anne-Marie Slaughter. 2001. International relations and compliance. In Handbook of international relations, ed. Walter Carlsnaes, Thomas Risse, and Beth Simmons, 538-554. London: SAGE Publications Limited.

Sen, Amartya. 2004. Elements of a theory of human rights. Philosophy and Public Affairs 34(4): 315-356.

Silverman, Arielle, Jason Gwinn, and Leaf Van Boven. 2015. Stumbling in their shoes: Disability simulations reduced judged capabilities of disabled people. Social Psychological and Personality Science 6(4): 464-471.

Springsted, Eric. 1986. Simone Weil and the suffering of love. Oregon: Crowley Publications Limited. 
Springsted, Eric. 1993. Rootedness, culture and value. In Simone Weil's philosophy of culture: Readings towards a divine humanity, ed. R. Bell, 161-188. Cambridge: Cambridge University Press.

Stein, Michael, and Janet Lord. 2008. The domestic incorporation of human rights law and the United Nations Convention on the rights of persons with disabilities. Washington Law Review Association 83: 449-479.

Stein, Michael, and Janet Lord. 2013. Prospects and practices for CRPD implementation in Africa. In African disability yearbook 1, ed. Charles Ngwena, Ilze Grobbelaar-du Plessis, Helene Combrinck, and Serges Djoyou Kamga, 97-113. Pretoria: Pretoria University Law Press.

Thomson-DeVeaux, Amelia. 2011. Looking with love: A feminist vision of Simone Weil. Thesis submitted to the Department of Religion, Princeton University, in partial fulfilment of the degree of Bachelor of Arts. New Jersey: Princeton University.

Waldron, Jeremy. 1988. When justice replaces affection: The need for rights. Harvard Journal of Law and Public Policy 11: 625-642.

Weil, Simone. 2002. The need for roots. Trans. Arthur Wills. Abingdon: Routledge.

Weil, Simone. 2005. Human personality. In Simone Weil: An anthology, ed. Sian Miles, 70-98. London: Penguin Books.

Weil, Simone. 2009. Waiting for God. Trans. Emma Craufurd. London: Harper Collins Publishers.

Winch, Peter. 1989. Simone Weil: The just balance. New York: Cambridge University Press.

World Health Organization. 2011. World report on disability. Geneva: World Health Organization. 